\title{
Gamma knife radiosurgery of epidermoid tumors: an analysis of treatment results of eight patients
}

\author{
Ryan L. Hellinger, Aizik L. Wolf, Beatriz Amendola, Sammie Coy \\ Innovative Cancer Institute, South Miami, Florida, United States \\ Miami Neuroscience Center, South Miami, Florida, United States
}

\begin{abstract}
Background: Epidermoid tumors (ETs) of the central nervous system (CNS) are rare tumors that typically occur in the $4^{\text {th }}$ decade. They typically grow around vital neurovascular structures which makes surgical treatment difficult. The objective of this paper is to report on the effectiveness and safety in the management of epidermoid tumors with gamma knife surgery (GKS). Materials and methods: This is a retrospective study of the medical records of 8 patients treated with GKS for epidermoid tumors between July 2010 to June 2019. The median prescription dose was $11 \mathrm{~Gy}$, ranging from 10 to $12 \mathrm{~Gy}, 5$ patients received the total dose target to the $50 \%$ line and 3 to the $55 \%$ isodose line. The mean tumor volume was $12.4 \mathrm{cc} \mathrm{ranging} \mathrm{from} 4.4$ to 24.8cc. The median follow-up time was 33.7 months and ranged from 0.9 to 58.8 months. At follow-up, patients were evaluated for neurological signs and symptoms and radiographic evidence of progression of disease. Two patients were treated after failure of linac stereotactic radiosurgery. One patient underwent stereotactic radiosurgery prior to GKS, and the other had failed surgical resection prior to GKS.

Results: The median age was 33 years old. There were two males and six females. The most common presenting manifestation was headaches followed by vision and hearing problems. Symptoms were resolved in all cases, except for one who had partial control of trigeminal neuralgia. All patients were locally controlled by imaging and neurological examination at first follow-up. Conclusion: Gamma knife surgery is a safe and effective alternative treatment in patients with CNS epidermoid tumors and should be included in the initial recommendation.
\end{abstract}

Key words: epidermoid tumor; radiosurgery; brain tumor; radiation therapy; surgery

Rep Pract Oncol Radiother 2021;26(5):683-687

\section{Introduction}

Epidermoid tumors (ETs) are benign rare, slow-growing lesions that account for roughly 0.2 to $1.8 \%$ of all intracranial tumors [1]. They have been described as "pearly" and "the most beautiful tumors in the body" [2]. This pearly appearance comes from their keratin and fatty acid contents and stratified epithelium lining [3]. It is believed they derive from the neural tube entrapping ectodermal cells during closure between the 3rd and 5th weeks of embryonic development [4]. They are most commonly located in the cerebellopontine angle (CPA), accounting for $40 \%$ of epidermoid tumor cases and tend to accumulate around vital neurovascular structures causing trigeminal neuralgia and hemifacial spasms to be common symptoms $[1,5]$.

Total resection is a common neurosurgical recommendation of these tumors; nonetheless, it is difficult to do so while preserving the neurovascu-

Address for correspondence: Beatriz Amendola, Innovative Cancer Institute, South Miami, FL 33143, United States;

e-mail: bamendola@innovativecancer.com

This article is available in open access under Creative Common Attribution-Non-Commercial-No Derivatives 4.0 International (CC BY-NC-ND 4.0) license, allowing to download articles and share them with others as long as they credit the authors and the publisher, but without permission to change them in any way or use them commercially 
lar structures it surrounds [2]. This makes partial resection necessary to preserve neurological function. However, partial removal of these tumors typically leads to recurrence and thus reoperation [3]. GKS may be the preferred alternative therapy. There have been very few studies reporting on the treatment of epidermoid tumors with GKS [4-6]. This study aims to offer insight into the effectiveness and safety of treating epidermoid tumors with gamma knife surgery, compared to surgical intervention, and provide distinct reasons why this may be a favored treatment option.

\section{Materials and methods}

This is a retrospective study of eight patients (two males and six females, ages ranging from 22 to 56 with a median age of 33) who were treated with GKS for epidermoid tumors from July 2010 to June 2018 at the Miami Neuroscience Center. One patient received a craniotomy, and another received stereotactic radiosurgery before GKS while the other six have only undergone GKS. Patients were diagnosed preoperatively with computed tomography (CT) scans and magnetic resonance imaging (MRI) of the brain. Presenting symptoms were recorded at the initial visit.

The Leksell Gamma Knife stereotactic frame was placed on each patient's head using lidocaine as local anesthesia after appropriate premedication with $1 \mathrm{~g}$ of cefazolin and $20 \mathrm{mg}$ of dexamethasone and intravenous sedation with propofol and midazolam. Imaging was based on MRI stereotactic localization of the lesion, visualization and volume dosimetry mapping. Radiosurgical treatment planning was done in conjugation with the radiation oncologist and the radiation physicist using gamma plan. The treatment plan consisted of an average of 22.4 isocenter. Treatment was carried out using the Perfexion Gamma Knife with a mean treatment time of 122 minutes (ranging from 48 minutes to 191 minutes). The median prescription dose was $11 \mathrm{~Gy}$, ranging from 10 to $12 \mathrm{~Gy}$, and five patients received the total dose target to the $50 \%$ and three to the $55 \%$ isodose line. The mean tumor volume was $12.4 \mathrm{cc}$ ranging from 4.4 to $24.8 \mathrm{cc}$.

The median clinical follow-up time was 33.7 months and ranged from 0.9 to 58.8 months. Patients follow-ups occurred in-person, except for one patient that followed up over the phone, and consisted of brain surveillance MRI imaging and clini- cal neurological evaluation after 1 month then in 3 -months and then every 6 months or if there were new or worsening symptoms. At follow-ups, patients were evaluated for neurological and radiological progression of the disease.Clinical status was assessed by a complete neurological exam and patient history while radiographic status was determined by measuring tumor volume in cubic centimeters via MRI imaging. Neurological and radiographic progression was then determined to be stable, improved or worsened based on the change in pretreatment to post-treatment status. Radiographic progression was defined as an increase in tumor volume and tumor control was defined as unchanged or decreased tumor volume. Symptom control was defined as stable or improved symptoms.

\section{Results}

The median age was 33 years old with two males and six females. Follow-up growth was recorded for all patients except one due to being lost to follow up. The most common tumor location was the cerebellopontine angle (6/8), with one extending from the prepontine cistern to the interpeduncular fossa and another extending to the left prepontine cistern (Tab. 1). There was one temporal fossa lesion and one posterior fossa lesion that extended from the foramen magnum to the prepontine cistern. Most of the lesions were on the left side (5/8; Tab. 1). Six patients presented headaches, making it the most common symptom (Fig. 1). Three patients presented vision difficulties (loss, diplopia, vision changes) and three patients presented hearing difficulties, including hearing loss and tinnitus. Two patients presented trigeminal neuralgia. while four patients experienced pain in other parts of their body, including the neck, back, and shoulder (Tab. 1). Some patients used medicine (paracetamol or ibuprofen) to relieve their pain but with only partial control. Accompanying symptoms included nausea, dizziness, lack of balance, fatigue, and tingling sensation in the face and head in five patients.

None of the patients developed side-effects after GKS. Of the six patients presenting with headaches, none reported headaches one month after the procedure. Three of the six developed recurrent headaches, one for seven months with partial local control, and the other 2 at 31 and 16 months until headaches were fully resolved. 
Table 1. Patients' backgrounds

\begin{tabular}{|c|c|c|c|c|c|c|c|}
\hline Pt. & $\begin{array}{c}\text { Age at } \\
\text { treatment }\end{array}$ & Sex & Surgical history & Location & Symptoms & $\begin{array}{c}\text { Total } \\
\text { volume [cc] }\end{array}$ & $\begin{array}{l}\text { Dose } \\
\text { [Gy] }\end{array}$ \\
\hline 1 & 39 & $\mathrm{~F}$ & Craniotomy & Right temporal fossa & $\begin{array}{l}\text { Headaches, blurred } \\
\text { vision, nausea }\end{array}$ & 7.8 & 12 \\
\hline 2 & 52 & $\mathrm{~F}$ & $\begin{array}{c}\text { Cyst removal of left } \\
\text { breast }\end{array}$ & $\begin{array}{l}\text { Left CPA extending to the } \\
\text { left prepontine cistern }\end{array}$ & $\begin{array}{c}\text { Headaches, tinnitus, } \\
\text { vision changes, dizziness }\end{array}$ & 24.8 & 11 \\
\hline 3 & 22 & $\mathrm{~F}$ & Radiosurgery & Left CPA & $\begin{array}{l}\text { Tinnitus, balance issues, } \\
\text { tingling in face }\end{array}$ & 13.7 & 10 \\
\hline 4 & 25 & $\mathrm{~F}$ & & Left CPA & $\begin{array}{c}\text { Headaches, hearing loss, } \\
\text { fatigue }\end{array}$ & 14.7 & 11 \\
\hline 5 & 28 & M & & Left CPA & Headaches & 13.7 & 12 \\
\hline 6 & 22 & $\mathrm{~F}$ & & $\begin{array}{l}\text { Posterior fossa cistern } \\
\text { extending from foramen } \\
\text { magnum to prepontine } \\
\text { cistern }\end{array}$ & Headaches & 9.4 & 11 \\
\hline 7 & 38 & M & & $\begin{array}{l}\text { Right CPA extending from } \\
\text { prepontine cistern to the } \\
\text { interpeduncular fossa }\end{array}$ & $\begin{array}{l}\text { Trigeminal neuralgia, } \\
\text { double vision, vision loss }\end{array}$ & 11 & 11 \\
\hline 8 & 56 & $\mathrm{~F}$ & Microdiscectomy & Left CPA & $\begin{array}{c}\text { Headaches, trigeminal } \\
\text { neuralgia }\end{array}$ & 4.4 & 11 \\
\hline
\end{tabular}

CPA - cerebellopontine angle

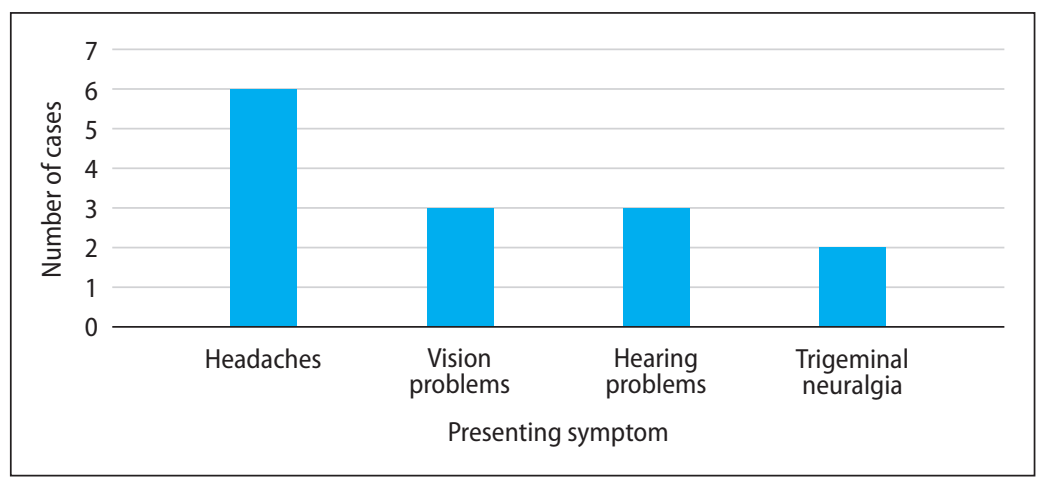

Figure 1. The most common presenting symptoms

One of the patients that presented with trigeminal neuralgia was only partially controlled 49 months after GKS. Another had recurring trigeminal neuralgia post GKS and was partially controlled by medications (carbamazepine), requiring a second GKS to the trigeminal nerve that resolved it after 18 months. Vision problems were resolved with all patients within one-month post GKS. Hearing problems were resolved in all cases. In one case, vision was resolved within a month and for the other two cases, the follow-up time was not recorded. All patients had tumor control or shrinkage (Tab. 2). One patient, in particular, experienced great reduction in tumor size, post GKS (Fig. 2). All accompanying symptoms were resolved in all patients.

\section{Discussion}

ET are benign unusual tumors that respond well and relatively fast to radiosurgery. In this retrospective study, GKS locally controls ET in all our cases with a median follow-up of 3 months.

Our results are consistent with data of prior ET GKS studies, including Vasquez et al., El-Shehaby et al., and Kida et al., with three, 12, and seven patients, respectively $[4,6]$. These studies observed patients as asymptomatic until about the fourth decade, consistent with our study showing an average age at the treatment of 35 years. Common symptoms have been reported to be headaches, trigeminal neuralgia, vision and hearing difficulties 
Table 2. Treatment outcomes

\begin{tabular}{|c|c|c|c|}
\hline Patient & Presenting symptoms & Growth & Follow up (months) \\
\hline 1 & Headaches, blurred vision & No & 0.9 \\
\hline 2 & Headaches, tinnitus, vision changes & No & 27.3 \\
\hline 3 & Tinnitus, balance issues, tingling in face & No & 52.4 \\
\hline 4 & Headaches, hearing loss & No & 11.8 \\
\hline 5 & Headaches & No & 31.2 \\
\hline 6 & Headaches & No & 58.8 \\
\hline 7 & Trigeminal neuralgia, vision problems & No & 36.1 \\
\hline 8 & Headaches, trigeminal neuralgia & No & 38.9 \\
\hline
\end{tabular}

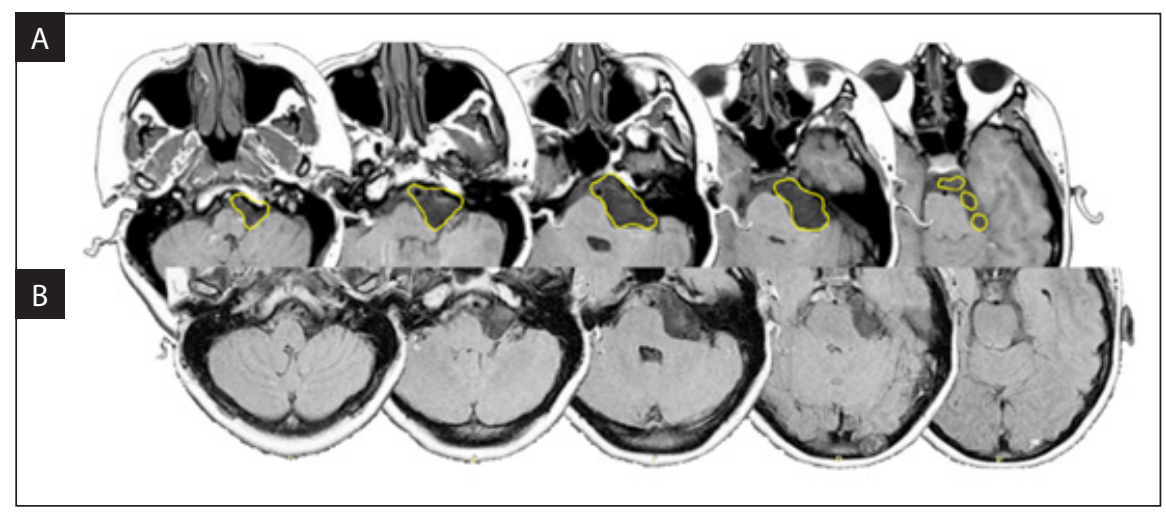

Figure 2. A. Pre-Gamma Knife MRI of patient 3 with a 13.7cc epidermoid tumor treated with 10Gy; B. Post-Gamma Knife MRI of patient 352.4 months showing tumor shrinkage

and seizures [4-5,7]. Unlike these other studies, our study does not have many patients reporting trigeminal neuralgia $(2 / 8)$ or seizures $(0 / 8)$.

Vasquez et al., El-Shehaby et al., and Kida et al. used a median prescription dose of $12 \mathrm{~Gy}, 11 \mathrm{~Gy}$, and mean of 14.6 Gy respectively. These studies reported complete relief or improvement in almost all patients. Except for El-Shehaby et al., who reported trigeminal pain uncontrolled in two patients and partially controlled in one [5]. Similarly, our study had one of the trigeminal patients with partially controlled pain. Furthermore, all studies reported tumor control in all cases. These other studies reported a similar average follow-up time of 10, 38, and 53 months, respectively, compared to our 33.14 months [4-6].

Many have published on the success of surgical resection of ETs, including Lynch et al., De Souza et al., Kato et al. and Chowdhury et al.; however, there is a debate on the best approach (Tab. 3) [2, 7-9]. Many studies argue total removal is the best approach because it is believed to prevent recur-

Table 3. Data from epidermoid tumor (ET) surgical intervention studies

\begin{tabular}{|l|c|c|c|c|c|c|c|c|}
\hline Author & $\begin{array}{c}\text { Year } \\
\text { of publication }\end{array}$ & $\begin{array}{c}\text { Number } \\
\text { of cases }\end{array}$ & \multicolumn{2}{c}{ Mortality (\%) } & Morbidity (\%) & GTR (\%) & $\begin{array}{c}\text { Recurrence } \\
(\%)\end{array}$ & $\begin{array}{c}\text { Follow-up } \\
\text { (months) }\end{array}$ \\
\hline Lynch et al. & 2014 & 33 & 0 & 42.42 & 72.7 & 9 & 86.4 \\
\hline De Souza et al. & 1989 & 30 & 3.7 & 40 & 18 & 14.8 & 108 \\
\hline Kato et al. & 2013 & 27 & 5 & 33.33 & 10 & 20 & N/A \\
\hline Chowdhury et al. & 2013 & 23 & 4.3 & 13.04 & 73.9 & N/A & 36 \\
\hline Overall & & 113 & 3.25 & 32.29 & 43.65 & 14.6 & 76.8 \\
\hline
\end{tabular}

GTR - gross tumor removal; N/A — non available 
rence $[2,7,9]$. However, difficulties arise due to Ets' proximity to the nerves and vascular structures [1, 2]. Partial removal appears to be a better option, but this could lead to recurrence. Therefore, GKS may be a more effective treatment.

While comparing cases of GKS and surgical treatment, GKS appears to be a better alternative when total removal does not seem possible or if there is a recurrence. GKS is a better alternative because it leads to a quicker recovery. The surgical treatment cases had an average follow-up time of 76.8 months (Tab. 3), while in the GKS studies, the average follow-up time was 33.53 months [2, 4-9]. GKS also has less recurrence, with only two out of the 30 cases $(6.67 \%)$ of the previously mentioned GKS studies and this one included, showing recurrent symptoms or tumor growth. While the surgical studies have a recurrence of $14.6 \%$. Furthermore, these studies report much higher morbidity of $32.29 \%$, while the previously mentioned GKS studies report lower morbidity (13.33\%) [2, 4-9].

Surgical removal could lead to permanent neurological deficits considering Ets' proximity to and encasement of vital structures, thereby making GKS a safer option $[1,2]$. Other papers report a low mortality rate of surgical intervention of ETs, but GKS still leads to lower mortality. In the previously mentioned studies, surgical intervention has a mortality rate of $3.25 \%$ compared to GKS having a mortality rate of $0 \%$ (Tab. 3). We hope that this data encourages patients to look at GKS as an option when surgery is not preferred or there is recurrent tumor growth.

There are limitations in this case series due to its retrospective nature and relatively small sample size. We recognize it is difficult to make recommendations for clinical practice due to the lack of a reference group. Prospective studies comparing GKS to another treatment method should be employed to make a more definitive recommendation on the use of GKRS but would be unlikely due to the low incidence of glomus jugulare tumors.

\section{Conclusion}

This data confirms that GKS is an effective treatment for ET and a viable alternative to surgical intervention. GKS can be offered as an upfront alternative treatment of ET in unresectable patients or patients with high surgical risk as local control is maintained and the morbidity remains low or nil. Although the numbers of this series is small and the follow-up is short, the results are encouraging. Further follow-up is needed.

\section{Conflict of interest}

None declared.

\section{Funding}

None declared.

\section{References}

1. Safavi-Abbasi S, Di Rocco F, Bambakidis N, et al. Has management of epidermoid tumors of the cerebellopontine angle improved? A surgical synopsis of the past and present. Skull Base. 2008; 18(2): 85-98, doi: 10.1055/s2007-991108, indexed in Pubmed: 18769651.

2. Lynch JC, Aversa A, Pereira C, et al. Surgical strategy for intracranial dermoid and epidermoid tumors: An experience with 33 Patients. Surg Neurol Int. 2014; 5: 163, doi: 10.4103/2152-7806.145764, indexed in Pubmed: 25558422.

3. Rehman L, Bokhari I, Siddiqi SUI, et al. Intracranial Epidermoid Lesions: our Experience of 38 Cases. Turk Neurosurg. 2017 [Epub ahead of print], doi: 10.5137/1019-5149. JTN.21095-17.0, indexed in Pubmed: 29091245.

4. Vasquez JA, Fonnegra JR, Diez JC, et al. Treatment of epidermoid tumors with gamma knife radiosurgery: Case series. Surg Neurol Int. 2016; 7(Suppl 4): S116S120, doi: 10.4103/2152-7806.176132, indexed in Pubmed: 26958427.

5. El-Shehaby A, Reda W, Karim KA, et al. Gamma knife radiosurgery for cerebellopontine angle epidermoid tumors. Surgical Neurology International. 2017; 8(1): 258, doi: 10.4103/sni.sni_206_17, indexed in Pubmed: 29184709.

6. Kida Y, Yoshimoto M, Hasegawa T, et al. [Radiosurgery of epidermoid tumors with gamma knife: possiblility of radiosurgical nerve decompression]. No Shinkei Geka. 2006; 34(4): 375-381, indexed in Pubmed: 16613218.

7. Chowdhury FH, Haque MR, Sarker MH. Intracranial epidermoid tumor; microneurosurgical management: An experience of 23 cases. Asian J Neurosurg. 2013; 8(1): $21-28$, doi: 10.4103/1793-5482.110276, indexed in Pubmed: 23741259.

8. deSouza CE, deSouza R, da Costa S, et al. Cerebellopontine angle epidermoid cysts: a report on 30 cases. J Neurol Neurosurg Psychiatry. 1989; 52(8): 986-990, doi: 10.1136/ jnnp.52.8.986, indexed in Pubmed: 2795068.

9. Kato $\mathrm{K}$, Ujiie $\mathrm{H}$, Higa $\mathrm{T}$, et al. Clinical presentation of intracranial epidermoids: a surgical series of 20 initial and four recurred cases. Asian J Neurosurg. 2010; 5(1): 32-40, indexed in Pubmed: 22028741. 